\title{
Sulfonated Styrene-Acrylic Acid Copolymers with pH-Indicator Property
}

\author{
Xin Fan, ${ }^{\circledR *, a, b}$ Ping Fan ${ }^{\circledR c}$ and Yuehuan $W^{b}$ \\ ${ }^{a}$ College of Chemistry and Chemical Engineering, Shanghai University of Engineering Science, \\ 201620 Shanghai, China \\ ${ }^{b}$ Department of Chemistry and Chemical Engineering, Taiyuan Institute of Technology, \\ Shan Xi, 030008 Taiyuan, China \\ ${ }^{c}$ School of Materials Science and Engineering, North University of China, \\ Shan Xi, 030051 Taiyuan, China
}

\begin{abstract}
In this study, a polymer $\mathrm{pH}$-indicator was synthesized by sulfonation of poly(styrene-coacrylic acid) with concentrated sulfuric acid. The synthesized polymer $\mathrm{pH}$-indicator exhibited $\mathrm{pH}$-responsive color changes in aqueous solutions, being purple in alkaline medium $(\mathrm{pH}<4)$, whereas yellow in acidic medium $(\mathrm{pH}>9)$. The sulfonation process extent and polymer color were affected by time and temperature of the process, as well as acrylic acid (AA) content. The addition of acrylic acid was a crucial point for color change due to the facility of cyclic ketone structure to turn into phenol under acidic condition. Compared with low molecule $\mathrm{pH}$-indicators, the sulfonated copolymer was prepared in form of films being repeatedly used as $\mathrm{pH}$-indicator and easily removed from the acid-base medium.
\end{abstract}

Keywords: polymers, sulfonated, pH-indicator, reusability

\section{Introduction}

$\mathrm{pH}$-indicator has been used in acidic-alkaline solutions for many years, playing a crucial role in many aspects, such as environmental detection, food freshness and $\mathrm{pH}$ sensors. ${ }^{1-8}$ It contains low molecular substances, including phenolphthalein, sulfonated phenolphthalein (phenol red and bromophenol blue), nitrophenols (paranitrophenol), azoic compound (methyl orange and toluylene red), ${ }^{9-11}$ dyestuff and plant pigments. ${ }^{12,13}$ However, these low molecular indicators are associated with certain disadvantage, like the complicated synthesis process, more severe pollution, lower stability, difficult immobilization and non-reusability. To overcome these drawbacks, some large molecular substances have been reported, ${ }^{14}$ such as pH-sensitive polymer, ${ }^{15-17}$ polymeric pH-indicators $^{18,19}$ and $\mathrm{pH}$-indicator-immobilized polymer. ${ }^{20,21}$ For example, Malik $^{22}$ synthesized sulfonated styrene-divinylbenzene copolymers with $\mathrm{pH}$-dependent color changes. The color changed from a darker color (in neutral water) to a brighter color (in 0.1 mol L-1 $\mathrm{NaOH}$ solution). ${ }^{22}$ Guo et al. ${ }^{23}$ prepared $\mathrm{pH}$-indicator plastic strips via co-polymerization of the

*e-mail: fanxintit@163.com imidazolium type ionic liquid monomer with acrylonitrile, that was exchanged with sulfonated anionic dyes. ${ }^{23}$ The color changed from orange red to yellow with the decrease of formic acid concentration from 5 to $5 \times 10^{-3} \mathrm{~mol} \mathrm{~L}^{-1}{ }^{23}$

In this study, a simple method was proposed to prepare the polymeric $\mathrm{pH}$-indicators. Poly(styrene-co-acrylic acid) was synthesized through emulsifier-free polymerization, sulfonated by concentrated sulfuric acid and dispersed in deionized water. Notably, obvious color changes of the sulfonated polymer were observed in different $\mathrm{pH}$ solutions. The factors influencing on the sulfonation extent of the copolymer and the reusability of the sulfonated copolymer were discussed. The color change points of the sulfonated copolymer in acidic-alkaline solutions were measured by UV-Vis spectrophotometer.

\section{Experimental}

Materials

Styrene (St), butyl acrylate (BA) and acrylic acid (AA) were all supplied by Sinopharm Chemical Reagent (Shanghai, China). The styrene was washed with sodium hydroxide solutions (5.0 wt.\%) for three times to remove 
inhibitors, and then dried over anhydrous calcium chloride for $48 \mathrm{~h}$. The initiator potassium persulfate (KPS), concentrated sulfuric acid $\left(\mathrm{H}_{2} \mathrm{SO}_{4}\right)$, sodium hydroxide $(\mathrm{NaOH})$ and sodium chloride $(\mathrm{NaCl})$ were also purchased from the Sinopharm Chemical Reagent (Shanghai, China), being that KPS was recrystallized from methanol.

\section{Synthesis}

Firstly, the St-AA copolymers were prepared by emulsifier-free polymerization (monomers:KPS: $\mathrm{NaCl}: \mathrm{H}_{2} \mathrm{O}$ ratio of 20:0.2:0.2:200) at $80{ }^{\circ} \mathrm{C}$ for $6 \mathrm{~h}$ under $\mathrm{N}_{2}$ atmosphere. The monomers using different styrene/ acrylic acid monomer feed ratio are shown in Table 1. The copolymer was separated by centrifugation and dried in vacuum to constant weight.

Table 1. Elemental composition of sulfonated copolymers with different sulfonation time and temperature

\begin{tabular}{lcccc}
\hline \multirow{2}{*}{$\begin{array}{l}\text { Sulfonation } \\
\text { time } / \mathrm{h}\end{array}$} & $\begin{array}{c}\text { Sulfonation } \\
\text { temperature } /{ }^{\circ} \mathrm{C}\end{array}$ & \multicolumn{3}{c}{ Elemental composition / \% } \\
\cline { 3 - 5 } 1 & 50 & 75.31 & 6.519 & 2.994 \\
3 & 50 & 63.73 & 6.252 & 6.127 \\
6 & 50 & 43.18 & 5.412 & 11.121 \\
12 & 50 & 44.27 & 4.312 & 10.813 \\
6 & 0 & 78.09 & 6.719 & 2.443 \\
6 & 30 & 69.01 & 5.989 & 4.601 \\
6 & 50 & 43.18 & 5.412 & 11.121 \\
6 & 70 & 40.18 & 4.914 & 15.894 \\
\hline
\end{tabular}

Secondly, the dried copolymer $(0.5 \mathrm{~g})$ was mixed with concentrated sulfuric acid $(6 \mathrm{~g})$ at different temperatures for varying hours. Afterwards, the sulfonated polymer was dispersed in deionized water $(50 \mathrm{~mL})$.

\section{Characterizations}

The Fourier transform infrared (FTIR) spectra of copolymers (before and after sulfonation) were recorded in an infrared spectrophotometer (PerkinElmer, SP-100) in $\mathrm{KBr}$ pellets. The $\mathrm{pH}$ measurements were carried out on a digital pH-meter (Hangzhou AoliLong Instruments Company, China). The zeta potentials were measured on dynamic light scattering (Malvern, 2S-Nano-S), using water as dispersion medium. The UV absorbances were obtained in a UV-Vis spectrophotometer (Persee TU-1900 spectrophotometer). The elemental analyses were carried out on the elemental analyzer (Elemental Analyser, vario EL). The solid-state ${ }^{13} \mathrm{C}$ nuclear magnetic resonance (NMR) spectrum was recorded in a Bruker equipment, model DRX 400 , with acquisition time of $3 \mathrm{~h}$ to clarify the structure of the copolymer.

\section{Results and Discussion}

Phenomenon of the color change of the sulfonated copolymer

The St-AA copolymers containing 10\% AA were sulfonated by concentrated sulfuric acid and dispersed in deionized water. The colors of the sulfonated copolymer suspensions at various $\mathrm{pH}$ are shown in Figure 1. As it can be seen, the yellow color vanished and the suspension became gray with the $\mathrm{pH}$ increase, changing to purple at the $\mathrm{pH}$ higher than 9.

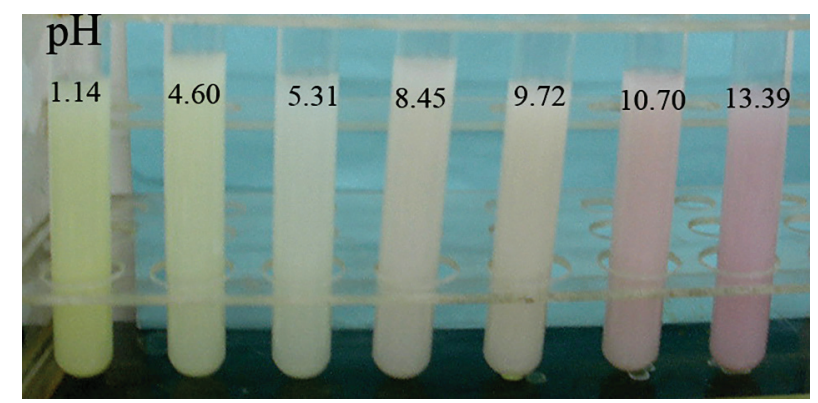

Figure 1. Photograph of the color of the sulfonated copolymer suspension at various $\mathrm{pH}$ values.

\section{Relationship of copolymer sulfonation extent with time}

The sulfonation temperature was fixed at $50^{\circ} \mathrm{C}$, and the St-AA copolymers containing $10 \%$ AA were sulfonated for different sulfonation time. Generally, the color of the sulfonated polymer was deeper with the longer sulfonation time (Figure 2c). Two reactions took place simultaneously in this process, the acylation reaction and the sulfonation reaction. As for the acylation reaction, the concentrated sulfuric acid accelerated the rate of Friedel-Craft acylation reaction. The St-AA copolymers were random copolymer, one or two acrylic acids in each styrene unit. The carboxylic acid reacts with benzene ring to form a cyclic ketone in Friedel-Craft acylation reaction, ${ }^{18}$ and since sulfuric acid was used in excess in this reaction, the impact of sulfuric acid in acylation reaction was ignored. With regard to the sulfonation reaction, longer sulfonation time elevated the sulfonation extent. As it is known, $-\mathrm{C}=\mathrm{O}$ was a chromophore group while $-\mathrm{SO}_{3} \mathrm{H}$ was an auxochrome group that was in the polymer chain, along with darker color of the sulfonated copolymer. The $-\mathrm{SO}_{3} \mathrm{H}$ content was characterized by $\mathrm{S}$ content via elemental analysis. It can be clearly seen that the highest $\mathrm{S}$ content was attained for $6 \mathrm{~h}$ (Table 1). The 
FTIR and the zeta potential results also verified the finding (Figure 2). The absorption peak at $1490 \mathrm{~cm}^{-1}$ was generated by the benzene rings $(\mathrm{Ph})$ that did not change during the whole process, and $-\mathrm{S}=\mathrm{O} / \mathrm{Ph}$ was used to demonstrate the sulfonation extent according to the semi-quantitative method. The peak at $1150 \mathrm{~cm}^{-1}$ corresponding to $\mathrm{S}=\mathrm{O}$ asymmetric stretching from $-\mathrm{SO}_{3} \mathrm{H}$ group derived from the sulfonation reaction. Notably, the peak height ratio of $-\mathrm{S}=\mathrm{O} / \mathrm{Ph}$ was the highest for $6 \mathrm{~h}$, being consistent with the elemental analysis results. This is because that, with the sulfonation time going, the sulfonated chains were more easily detached from the main chain, being attributed to the ionization and electrostatic repulsion in the solvent. ${ }^{24}$ Moreover, the $-\mathrm{SO}_{3} \mathrm{H}$ groups were in the polymer chains, and the zeta potential was lower in Figure 2c.

\section{Relationship of copolymer sulfonation extent with temperature}

The St-AA copolymer containing 10\% AA was sulfonated at varying temperatures for $6 \mathrm{~h}$, and the photograph of the sulfonated suspension is shown in Figure 3b. It was found that the color of copolymer was deeper with the temperature increase. When the sulfonation temperature was $0{ }^{\circ} \mathrm{C}$, the color of the copolymer was white and there was no obvious absorption peak at $1150 \mathrm{~cm}^{-1}$ belonging to $-\mathrm{S}=\mathrm{O}$ (Figure 3a). Compared with the spectrum of polymer template, the peak intensity at $1150 \mathrm{~cm}^{-1}$ was stronger with the sulfonated temperature increase. The content of $\mathrm{S}$ was the highest at $70{ }^{\circ} \mathrm{C}$ and very low at 0 or $30{ }^{\circ} \mathrm{C}$ (Table 1). This happens because the molecular motion was accelerated by the elevated temperature and $\mathrm{H}_{2} \mathrm{SO}_{4}$ was more likely reacted with the polymer chains. Also, the zeta potential lowed, as seen in Figure 3b, due to the more $-\mathrm{SO}_{3} \mathrm{H}$ group entering into the benzene ring.

\section{Relationship of copolymer sulfonation extent with $A A$ concentration}

The copolymers with different ratios of AA $(0,1$, $2.5,5,10$ and $20 \%$ in total monomer) were sulfonated at $70{ }^{\circ} \mathrm{C}$ for $6 \mathrm{~h}$, and the states of the sulfonated polymer are shown in Figure 4a. $1 \mathrm{~mL}$ of sulfonated suspension with different AA contents was added into the alkaline solution, and the $\mathrm{pH}$ value was adjusted to 10 . As it can be seen in Figure 4b, the color of the sulfonated suspension
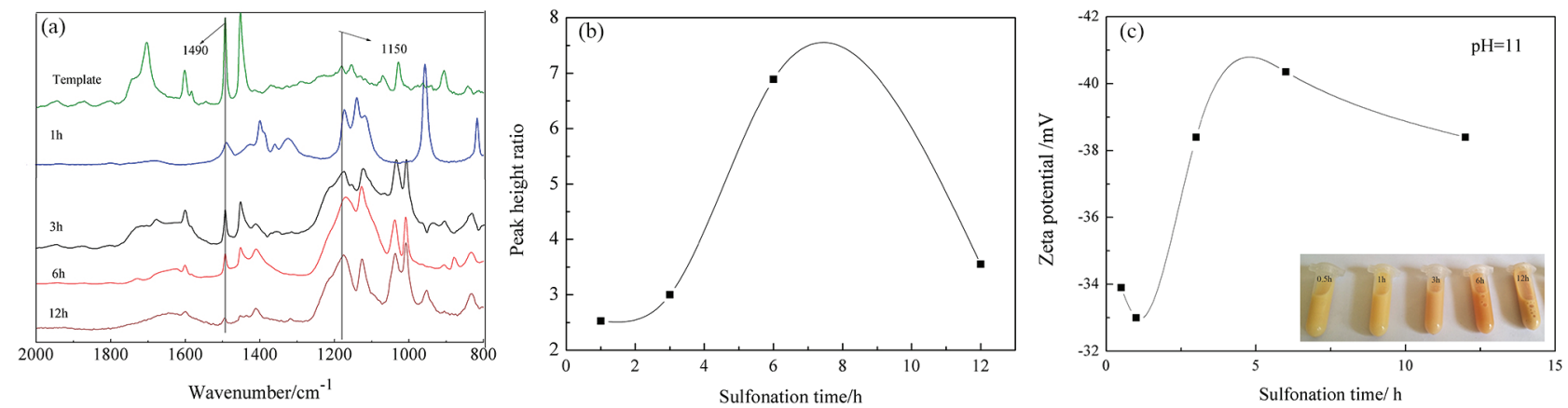

Figure 2. (a) The FTIR spectra of the PSt-AA copolymer and the sulfonated copolymers with different sulfonation times (1,3, 6 and $12 \mathrm{~h}$ ); (b) the peak height ratio of $-\mathrm{S}=\mathrm{O} / \mathrm{Ph}$ with sulfonation time, and (c) zeta potentials and the respective states of the sulfonated copolymers according to the sulfonation times.
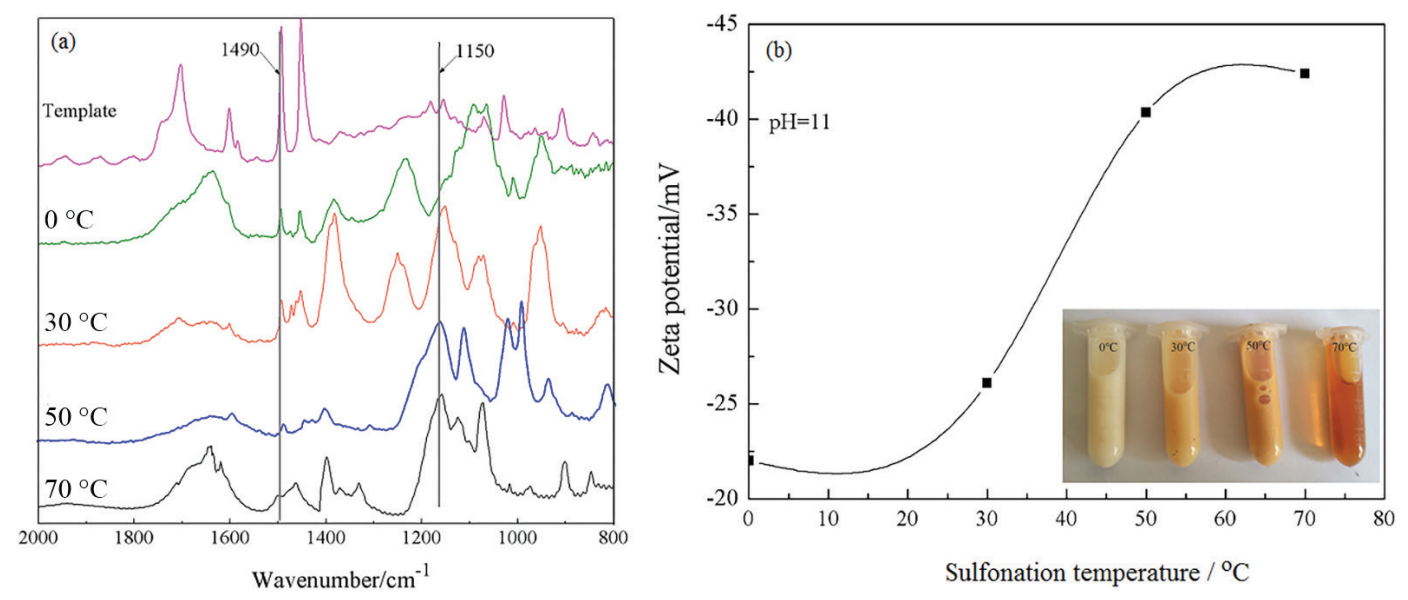

Figure 3. (a) FTIR spectra and (b) zeta potentials and the respective states of the sulfonated copolymers according to the sulfonation temperature $(0,30$, 50 and $\left.70{ }^{\circ} \mathrm{C}\right)$. 
became purple, except the polymer with $0 \%$ AA content. Since the carboxylic acid reacted with the benzene ring to form a cyclic ketone, the resultant conjugated ketone can be easily turned into the phenolic group in acidic medium (Scheme 1). Moreover, the phenolic group was changed into the form of quinone in alkaline medium, and the color of the sulfonated polymer was changed from yellow to pink. The characteristic peak of the conjugated ketone was at $1630 \mathrm{~cm}^{-1}$ (Figure 4c), and the absorption ketone peaks were stronger with the increase of AA amount. For the sulfonated polymer with $0 \% \mathrm{AA}$, the color did not change due to the absence of conjugated ketone or phenol, being confirmed by the infrared results in Figure 4c. The structure of the sulfonated copolymer (20\% AA) was characterized by solid-state ${ }^{13} \mathrm{C}$ NMR spectroscopic analysis (Figure $4 \mathrm{~d}$ ). The copolymer showed chemical shifts at $38\left(\mathrm{C}_{1}\right)$ and $124 \mathrm{ppm}\left(\mathrm{C}_{3}\right)$ due to the aliphatic carbon atoms and the carbons at the benzene ring, respectively. The peak at $73 \mathrm{ppm}\left(\mathrm{C}_{2}\right)$ is attributed to the tertiary atoms at the trunk chain. The peak at $144 \mathrm{ppm}$ $\left(\mathrm{C}_{4}\right)$ can be assigned to the carbons of the $-\mathrm{SO}_{3} \mathrm{H}$ group at the benzene ring, proving the introduction of $-\mathrm{SO}_{3} \mathrm{H}$ group into the benzene ring after sulfonation. The peak at $229 \mathrm{ppm}\left(\mathrm{C}_{5}\right)$ for the unsaturated ketone confirmed that the carboxyl group acylated to form the hexagon ring.

The UV-Vis spectra of the sulfonated copolymer $(20 \%$ $\mathrm{AA}, \mathrm{A} 1)$ solutions in acidic ( $\mathrm{pH} 1)$ and alkaline solutions (pH 10) are displayed in Figure 5a. Clearly, the sulfonated copolymer showed the intense peak at $450 \mathrm{~nm}$ in acidic solution, and at $550 \mathrm{~nm}$ in alkaline medium. It was observed that the plot of absorbance at 450 or $550 \mathrm{~nm}$ was increased with the AA concentration increase (Figure 5b). This takes place because the conjugated ketone was easily to be obtained with the unit of AA with the copolymer chain increase. To find out the change points, the absorptions of A1 in different $\mathrm{pH}$ solutions were measured at 450 and $550 \mathrm{~nm}$ (Figure 5c), and suggested that the color change point in acidic solution was at $\mathrm{pH} 4$, while in alkaline solution at $\mathrm{pH} 9$, respectively.

The reusability of sulfonated copolymer film in acid-alkali solution

The reusability of the sulfonated film is shown in Figure 6. Typically, the St-AA-BA copolymer was prepared by emulsifier-free polymerization (St:AA:BA ratio of 8.9:1.76:10.21 in g). In brief, the monomer BA was added in polymerization to reduce the glass transition temperature, and the copolymer formed a film at room temperature $\left(25^{\circ} \mathrm{C}\right)$. Subsequently, the film was sulfonated in concentrated sulfuric acid for $6 \mathrm{~h}$ at $70{ }^{\circ} \mathrm{C}$, washed with deionized water to remove sulfuric acid, and then immersed in $0.1 \mathrm{~mol} \mathrm{~L}^{-1}$ acid solution and $0.1 \mathrm{~mol} \mathrm{~L}^{-1}$ alkaline solution for ten times (Figure 6). The color of sulfonated copolymer still changed after ten times, indicating favorable reusability.
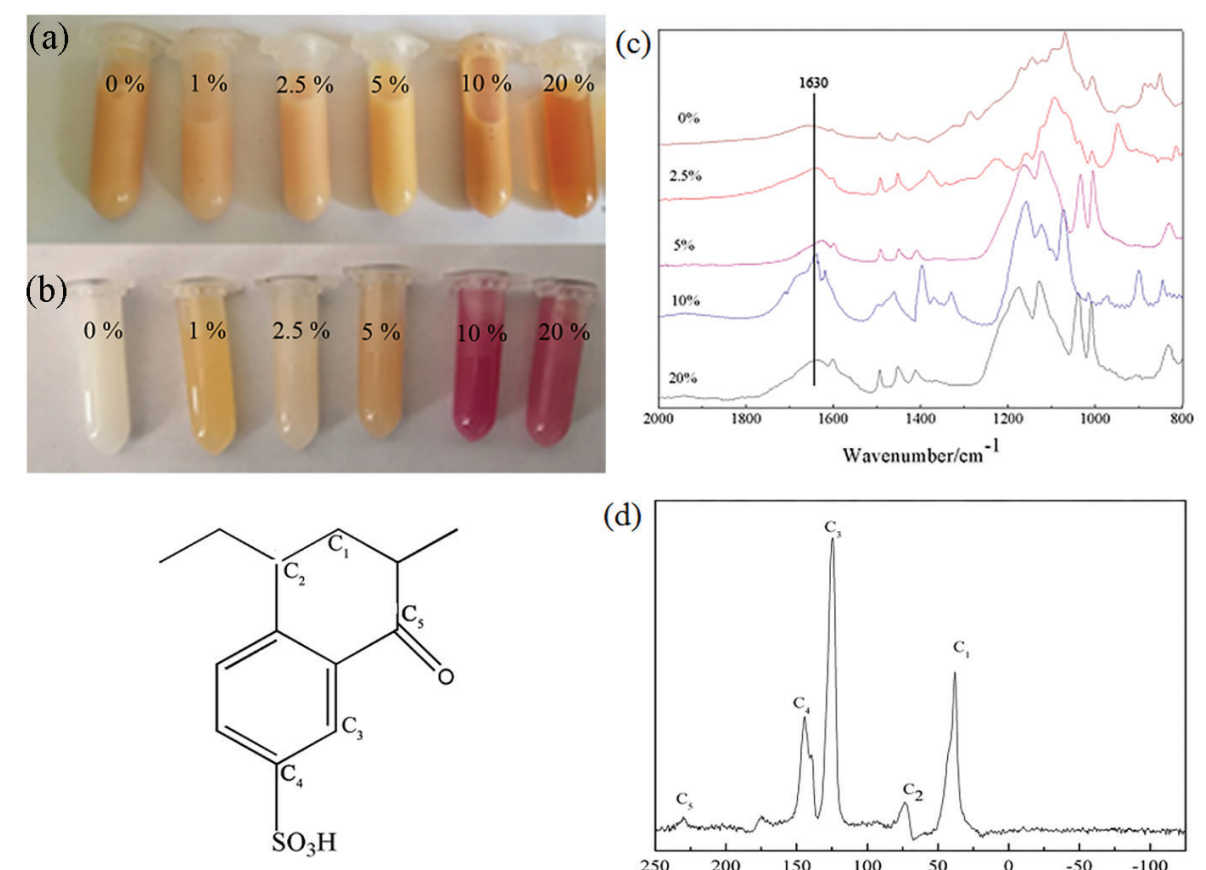

(d)

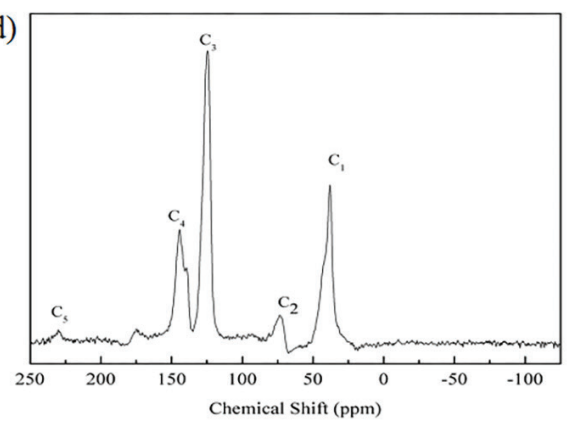

Figure 4. The states of the vary AA percentages of sulfonated copolymer (a) in acid solution (the AA ratio of $0,1,2.5,5,10$ and $20 \%$ ), and (b) in alkaline solution; (c) FTIR spectra of the sulfonated copolymer as function of AA amount, and (d) solid-state ${ }^{13} \mathrm{C}$ NMR analysis of the sulfonated copolymer (20\% AA). 


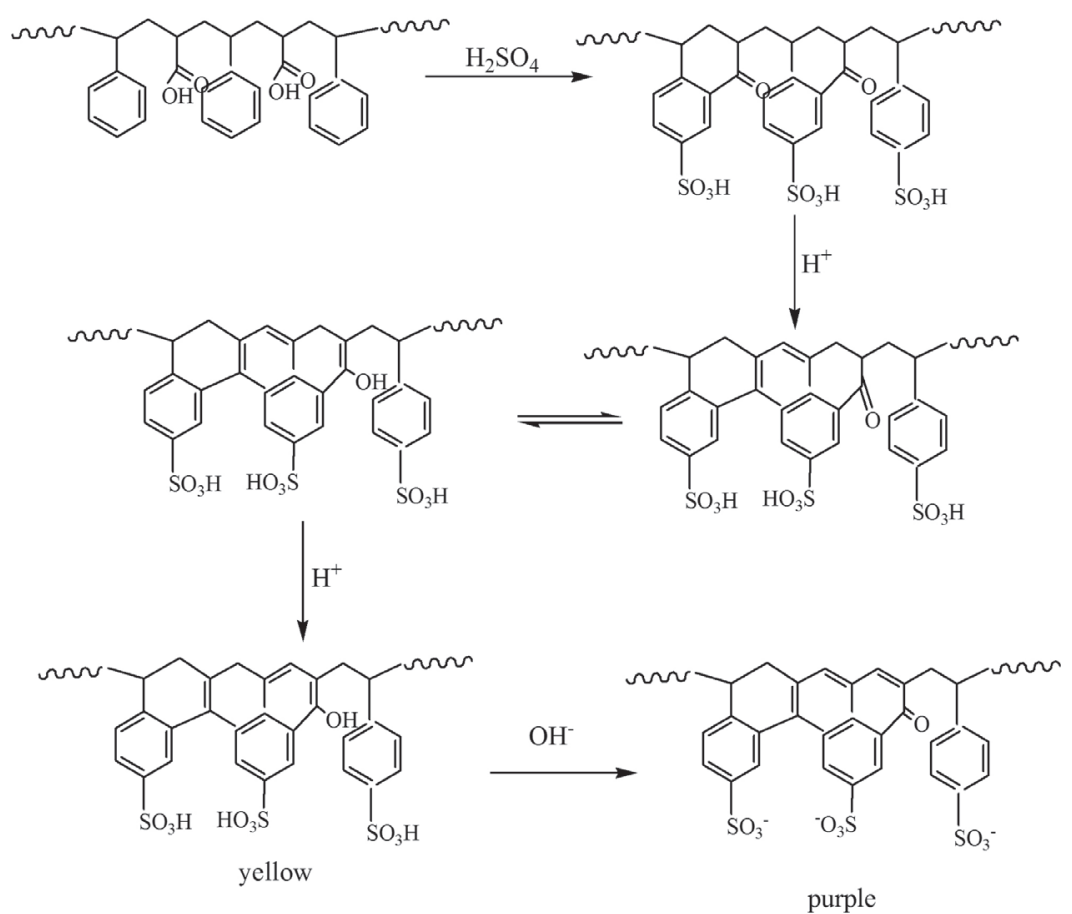

Scheme 1. Mechanism for the color change of sulfonated polymer. ${ }^{25}$
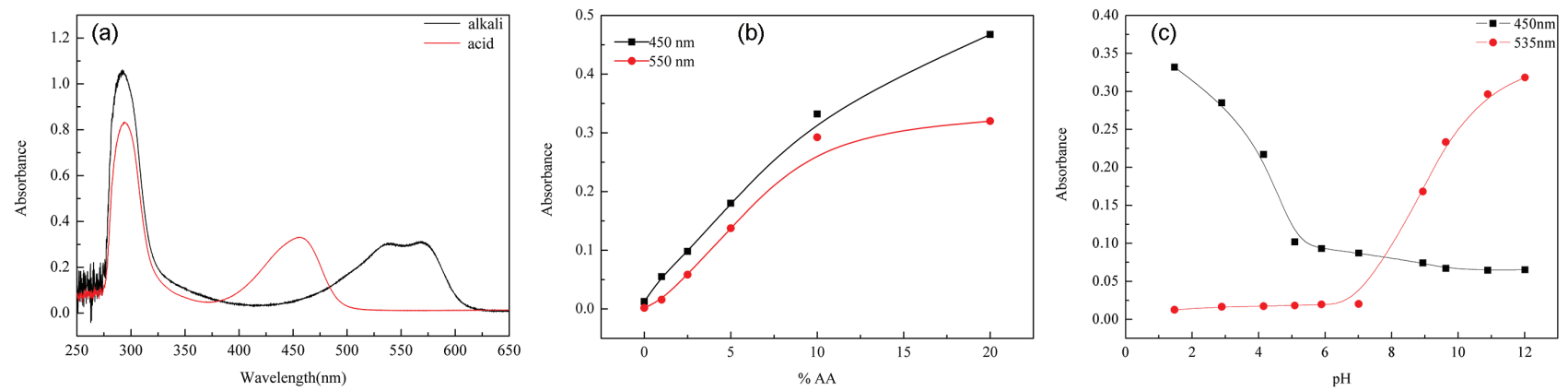

Figure 5. (a) Absorbance spectra of the sulfonated copolymer (20\% AA, A1) in acid and alkali solutions, (b) plots of the absorbance (at 450 and $550 \mathrm{~nm}$ ) of the sulfonated polymer with different amounts of AA in acid and alkaline medium, and (c) plots of the absorbance of A1 polymer solution at 450 and $535 \mathrm{~nm}$ as function of the $\mathrm{pH}$ value.

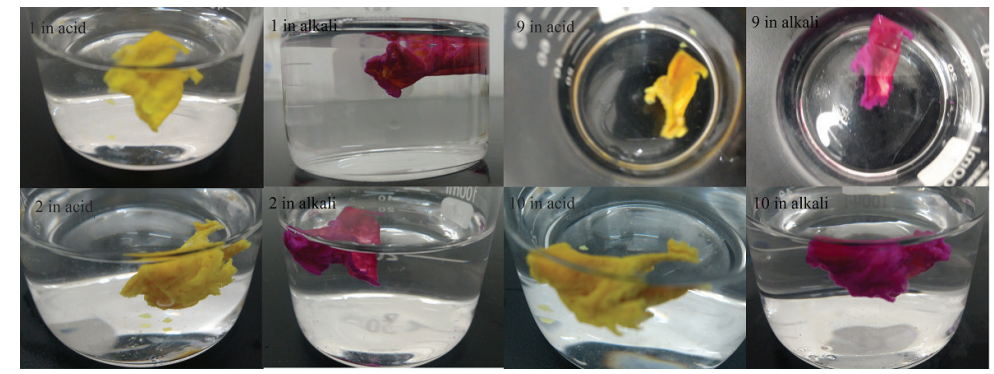

Figure 6. The sulfonated copolymer immersed in acid-alkali solutions for 10 times.

\section{Conclusions}

In this study, a polymer with $\mathrm{pH}$-indicator properties was synthesized by St-AA copolymers and sulfonated in concentrated sulfuric acid. The color of the sulfonated polymer became darker with the time and temperature increases, as well as the AA content, of the sulfonation process. More importantly, the sulfonated St-AA-BA copolymer film also possessed $\mathrm{pH}$-indicator properties, and was re-used, circularly changing from yellow to purple in the acidic-alkaline solutions after ten times. The $\mathrm{pH}-$ responsive polymer film is promising to be applied in the environment, water and chemical industries. 


\section{Supplementary Information}

Supplementary data (TEM images of sulfonated copolymer) are available free of charge at http://jbcs.sbq.org.br as PDF file.

\section{Acknowledgments}

This work was supported by the Start-Up Funds of Shanghai University of Engineering Science, the Key Research Plan Program of Shanxi Province (No. 201603D421038), Shanxi Province Foundation for Returness (2016-114).

\section{References}

1. Kuswandi, B.; Nurfawaidi, A.; Food Control 2017, 82, 91.

2. Prietto, L.; Pinto, V. Z.; El Halal, S. L. M.; de Morais M. G.; Costa, J. A. V.; Lim, L. T.; Dias, A. R. G.; Zavareze, E. D. R.; J. Sci. Food Agric. 2018, 98, 2735.

3. Sun, W.; Li, H.; Wang, H.; Xiao, S.; Wang, J.; Feng, L.; Talanta 2015, 143, 127.

4. Chung, H. J.; Sulkin, M. S.; Kim, J. S.; Goudeseune, C.; Chao, H. Y.; Song, J. W.; Yang, S. Y.; Hsu, Y. Y.; Ghaffari, R.; Efimov, I. R.; Rogers, J. A.; Adv. Healthcare Mater. 2014, 3, 59.

5. Salvo, P.; Calisi, N.; Melai, B.; Cortigiani, B.; Mannini, M.; Caneschi, A.; Lorenzetti, G.; Paoletti, C.; Lomonaco, T.; Paolicchi, A.; Scataglini, I.; Dini, V.; Romanelli, M.; Biosens. Bioelectron. 2017, 91, 870.

6. Lydia, A. P.; Qi, Y.; Brigitte, F. S.; Dmytro, K.; Saumya, S.; Mads, B. L.; Simon, C. W.; Laura, K.; Marcel, P. B.; Biochemistry 2018, 57, 861.

7. Lin J.; Chen, X.; Chen, C.; Hu, J.; Zhou, C.; Cai, X.; Wang, W.; Zheng, C.; Zhang, P.; Cheng, J.; Guo, Z.; Liu, H.; ACS Appl. Mater. Interfaces 2018, 10, 6124.
8. Shao, F.; Zhang, L.; Jiao, L.; Wang, X.; Miao, L.; Li, H.; Zhou, F.; Anal. Chem. 2018, 90, 8673.

9. Zhang, Q.; Zhang, S.; Liu, S.; Ma, X.; Lu, L.; Deng, Y. S.; Analyst 2011, 136, 1302.

10. Sakai, N.; Mareda, J.; Vauthey, E.; Matile, S.; Chem. Commun. 2010, 46, 4225.

11. Cardona, M. A.; Magri, D. C.; Tetrahedron Lett. 2014, 55, 4559.

12. Forster, M.; J. Chem. Educ. 1978, 55, 107.

13. Vankar, P. S.; Bajpai, D.; Electron. J. Environ. Agric. Food Chem. 2010, 9, 875.

14. Bleha, M.; Plichta, Z.; Votavova, E.; Kalal, J.; US Pat. 4166804A, 1979.

15. Ramírez, E.; Burillo, S. G.; Barrera-Díaz, C.; Roa, G.; Bilyeu, B.; J. Hazard. Mater. 2011, 192, 432.

16. Cho, E. C.; Lim, H. J.; Kim, H. J.; Son, E. D.; Choi, H. J.; Park, J. H.; Kim, J. W.; Kim, J.; Mater. Sci. Eng., C 2009, $29,774$.

17. Tang, L.; Zhu, L.; Wang, Y.; Fang, C.; J. Phys. Chem. Lett. 2018, 9, 4969.

18. Mathew, A.; Deb, P. C.; Macromol. Chem. Phys. 1998, 199, 2527.

19. Ratna, D.; Dalvi, V.; Chakraborty, B. C.; J Appl. Polym. Sci. 2007, 104, 1517.

20. Liu, Z.; Liu, J.; Chen, T.; J. Polym. Sci., Part A: Polym. Chem. $\mathbf{2 0 0 5}, 43,1019$.

21. Kim, J.; Cho, T. N.; Valdés-Ramírez, G.; Wang, J.; Talanta 2016, 150,622 .

22. Malik, M. A.; Ind. Eng. Chem. Res. 2009, 48, 6961.

23. Guo, J.; Qiu, L.; Deng, Z.; Yan, F.; Polym. Chem. 2013, 4, 1309.

24. Fan, X.; Niu, L.; Wu, Y.; Cheng, J.; Yang, Z.; Appl. Surf. Sci. 2015, 332, 393.

25. Ratna, D.; Dalvi, V.; Chakraborty, B. C.; Deb, P. C.; J. Polym. Sci., Part A: Polym. Chem. 2003, 41, 2166.

Submitted: January 15, 2019

Published online: May 22, 2019 